\title{
Steroid-induced Glaucoma
}

\author{
Tanuj Dada, Soman Nair, Munish Dhawan
}

Dr RP Center for Ophthalmic Sciences, All India Institute of Medical Sciences, New Delhi, India

Steroid-induced glaucoma is a form of open-angle glaucoma occurring as an adverse effect of corticosteroid therapy. ${ }^{1}$ It is usually associated with topical steroid use, but it may develop with oral, intravenous, inhaled, or periocular steroid administration by causing decrease in aqueous outflow facility. A number of drugs have been implicated in corticosteroid-induced glaucoma including dexamethasone, betamethasone, prednisolone, medrysone, fluoromethalone, hydrocortisone, cortisone, etc. Glucocorticoids may exert their effect by increased expression of the MYOC (TIGR) gene at Locus GLC1A . ${ }^{2}$

\section{INCIDENCE}

Steroid-responsive intraocular pressure (IOP) elevations can occur in people of all ages, although children are less frequently reported to have IOP elevation with steroids. ${ }^{3}$ No gender and racial predilection exists for steroid-responsive glaucoma.

Incidence of steroid-induced IOP elevation in patients on systemic corticosteroids is unknown because most of these patients do not have their IOP checked.

These patients may be discovered during a routine eye exam while on medication, or the glaucoma may have progressed to the point of causing visual symptoms. Patients taking topical steroid drops usually receive follow-up care by an ophthalmologist who monitors IOP. Approximately one-third of individuals experience moderate increase in IOP after topical steroid use. However, 5-6\% of normal population develops a marked increase of IOP after 4-6 weeks of topical steroid therapy..$^{4-7}$ Thus, $5 \%$ of the general population is considered to be "steroid responder", i.e. may develop steroid-induced glaucoma when steroids are administered. This is shown by studies conducted by Armaly and Becker (Table 1).

\section{RISK FACTORS}

\section{Patient Related}

Persons with pre-existing primary open-angle glaucoma have a much greater potential to experience an elevated IOP from topical corticosteroids. On the other hand normal individuals classified as high steroid responders are more likely to develop POAG. ${ }^{5-10}$

Patients with primary chronic angle closure and patients with secondary open-angle glaucoma behave similarly to normal eyes with regard to steroid response. ${ }^{11}$
Table 1: IOP reponse to topical corticosteroid administration

\begin{tabular}{lll}
\hline & Armaly $^{5-7}$ & Becker $^{4}$ \\
\hline Frequency & QID & TDS \\
Duration & 6 weeks & 4 weeks \\
Parameter & Final IOP & IOP Change \\
Type of Responder & IOP (mm Hg) & IOP (mm Hg) \\
Low & $<20(58 \%)$ & $<6(66 \%)$ \\
Intermediate & $20-31(36 \%)$ & $6-15(29 \%)$ \\
High & $>31(6 \%)$ & $>15(5 \%)$ \\
\hline
\end{tabular}

There are certain conditions which are associated with increased risk of steroid-induced glaucoma such as:

- Patients with primary open angle glaucoma ${ }^{9}$

- First degree relatives of POAG Patients ${ }^{12,13}$

- High myopia ${ }^{14}$

- Diabetes mellitus ${ }^{15}$

- Connective tissue disorders (especially rheumatoid arthritis) ${ }^{16}$

- Eyes with traumatic angle recession and their fellow eyes ${ }^{17}$

- $\quad$ Pigment dispersion syndrome ${ }^{18}$

- Endogenous hypercortisolism ${ }^{19}$

\section{Route of Administration}

Most cases of steroid-induced glaucoma occurs from exogenous steroids which may be given topically, periocularly or systemically. However, endogenous steroids can also cause this condition $^{19}$ (Table 2).

Table 2: Route of administration leading to steroid-induced glaucoma

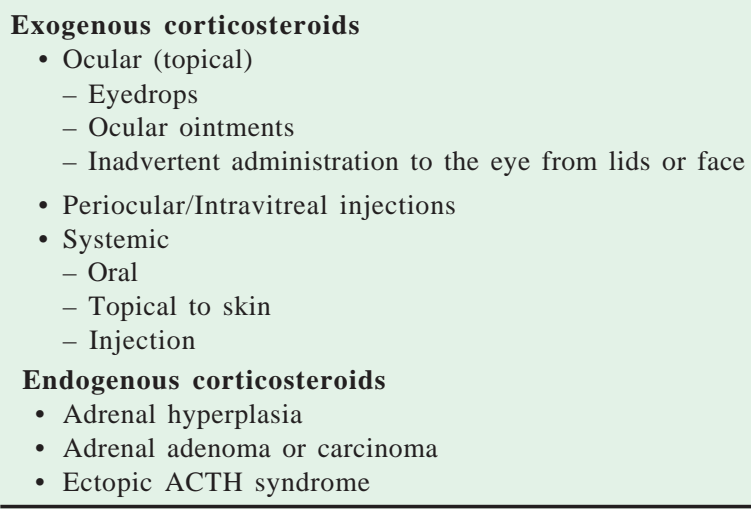


The number of people responding with an elevated IOP varies with the route of administration. More people respond from topically applied drops (including topically applied creams to the periorbital area). ${ }^{20,21}$ Periocular steroids, especially repository forms, are particularly dangerous due to their prolonged duration of action. ${ }^{22}$ A patient's response to topical steroids does not predict response to periocular steroids. ${ }^{23}$

IOP elevation after intravitreal triamcinolone injection is common and may take an extended period of time to manifest. After intravitreal injections of triamcinolone acetonide, an IOP elevation can develop in about $50 \%$ of eyes, starting about 1-2 months after the injection. In the vast majority, IOP can be normalized by topical medication, and returns to normal values without further medication about 6 months after the injection. A single intraoperative intravitreal injection of triamcinolone acetonide has been reported to be a safe and efficacious route of steroid delivery during phacoemulsification in patients with chronic idiopathic anterior uveitis or intermediate uveitis and is recommended as a substitute for postoperative oral steroid administration. However, it is known to result in ocular hypertension in almost $25 \%$ cases. ${ }^{24-26}$

Systemic administration of corticosteroids is least likely to induce glaucoma. However, the IOP elevation may occur as long as weeks to years after treatment. ${ }^{27}$

In order of decreasing frequency, incidence of elevated IOP is less with intravenous, parenteral, and inhaled routes of administration. It is reported that the response to systemic steroids does not correlate with the dosage or duration of treatment but is associated with the degree of pressure response to topical steroids. ${ }^{28}$

Even relatively new inhalational corticosteroid with excellent safety profile like Fluticasone propionate has been reported to cause a significant rise in IOP on short-term use, specially in patients predisposed to POAG. ${ }^{29}$

Elevated IOP may also be caused by increased endogenous corticosteroids as seen in Cushing's disease. ${ }^{19}$

\section{Steroid Formulation}

In general the pressure inducing effect of a topical steroid is proportional to its anti-inflammatory potency. Commonly used, potent corticosteroids like Betamethasone, Dexamethasone and Prednisolone have a significant tendency to induce glaucoma. ${ }^{30}$ Less potent steroids such as Fluorometholone and Medrysone are less likely to induce IOP elevations. ${ }^{31-32}$

The concentration or dose of a steroid is also related to the likelihood of producing an intraocular pressure elevation. In a study of high topical steroid responders, 0.01\% Betamethasone caused significantly less pressure elevation than the $0.1 \%$ concentration. $^{33}$

\section{Duration of Steroid Administration}

Patients who receive corticosteroid therapy may develop IOP elevations in days, weeks, months or years after initiating treatment. The period required and the magnitude of IOP rise depends on the various factors described above. Topical corticosteroids typically produce IOP elevation within 2 to 6 weeks. ${ }^{4-7}$ Systemically administered steroids, however, may take longer duration to elicit an IOP rise. ${ }^{25}$

\section{PATHOPHYSIOLOGY}

Corticosteroids cause elevation of the IOP by decreasing the facility of aqueous outflow. ${ }^{9,34}$ Steroid specific receptors on the trabecular meshwork cells may play a role in the development of steroid-induced glaucoma. ${ }^{35}$ Recent research has elucidated the possible role of genetic influences in the pathophysiology. ${ }^{2}$

The main mechanism of action of steroids that is responsible for glaucoma is their membrane stabilizing action. ${ }^{36}$ Hyaluronidase sensitive glycosaminoglycans (mucopolysaccharides) are normally present in the aqueous outflow system. These glycosaminoglycans in the polymerized form may undergo hydration producing a "biologic edema”. Hence, these are constantly degraded by the hyaluronidase within the lysosomes of the goniocytes.

The steroids stabilize the lysosomal membrane of the goniocytes and thus lead to an accumulation of polymerized glycosaminoglycans in the trabecular meshwork, producing an increased outflow resistance. ${ }^{37,38}$ Glucocorticoid administration increases expression of collagen, ${ }^{39}$ elastin, ${ }^{40}$ and fibronectin ${ }^{41}$ within the trabecular meshwork and induces expression of sialoglycoprotein. ${ }^{42}$

Another mechanism proposed is that steroids inhibit phagocytosis by the endothelial cells lining the trabecular meshwork. This leads to an accumulation of debris within the meshwork. ${ }^{43}$ There is also extracellular deposition of fingerprintlike material.

Steroid use decreases expression of extracellular proteinases including fibrinolytic enzymes and stromolysin.

A decrease in the synthesis of prostaglandins by corticosteroids, that regulate aqueous facility has also been proposed as one of the mechanisms leading to increase in IOP. ${ }^{30}$

\section{GENETIC INFLUENCES}

In an experiment involving exposure of cultured trabecular meshwork cells to dexamethasone, delayed increase in expression of a gene product was observed. ${ }^{2}$ This protein was termed "trabecular meshwork inducible glucocorticoid reponse” protein, initially localized to the GLC1A locus on chromosome 1q25 and subsequently linked to the myocilin gene (MYOC). 
The MYOC gene spans approximately $17 \mathrm{~kb}$ and contains three exons transcripting a $2.3 \mathrm{~kb}$ gene product. Within the trabecular meshwork, it is equally expressed in the trabecular meshwork cells from the juxtacanalicular, corneoscleral and uveal layers. Normal myocilin expression is increased in response to elevated IOP, dexamethasone exposure and other forms of trabecular stress implying that it may have a protective role in the outflow pathway. ${ }^{44}$

Myocilin gene mutations result in the formation of abnormal gene products which when produced in larger concentrations may lead to trabecular meshwork clogging and increased IOP. In human trabecular meshwork cell cultures treated with dexamethasone the TIGR/MYOC protein colocalises with components of the extracellular matrix like fibronectin and laminin. This could alter cell matrix interactions in the trabecular meshwork. ${ }^{45}$ The mutated gene product also suppresses normal myocilin secretion. However, a recent study conducted in steroid responders failed to identify a statistically significant association between myocilin variations and steroid response. ${ }^{4}$

\section{ULTRASTRUCTURAL CHANGES IN THE TRABECULAR MESHWORK}

The main finding in steroid-induced glaucoma is an accumulation of basement membrane-like material staining for type IV collagen. These accumulations are found throughout all layers of the TM. Glucocorticoids affect TM cell morphology by increasing synthesis of endoplasmic reticulum, golgi complexes, secretory vesicles, and increased cell and nuclear size. There is an increased deposition of extracellular matrix, thickened trabecular beams and increased expression of fibronectin and laminin. Formation of cross-linked actin networks, microtubule tangles, increased actin binding proteins and an altered gap junction morphology have also been noted. There is an increased expression of MYOC (TIGR) gene and decreased expression of matrix metalloproteinases .This results in altered TM cell function, namely, inhibition of phagocytosis, proliferation and migration, resulting in altered outflow facility.

\section{CLINICAL FEATURES}

In steroid-induced glaucoma, the pressure elevation is gradual. Therefore, like primary open-angle glaucoma, very few symptoms exist. History of systemic or ocular disease, which could require chronic corticosteroid use (e.g. uveitis, collagen vascular disease, asthma, dermatitis) should be elicited in patients having open angle glaucoma.

The age of the patient may determine the clinical form of corticosteroid-induced glaucoma. Infants may present with features of congenital glaucoma having tearing, photophobia, blepharospasm, cloudy corneas, buphthalmos, elevated IOP and optic disk cupping. Unlike congenital glaucoma, however, the anterior chamber angle is normal. ${ }^{46}$ Teenagers and adults usually present with features of primary open angle glaucoma with decreased outflow facility. Clinical evaluation reveals an elevated IOP, open and normal appearing angles on gonioscopy, painless white eye, optic disk cupping and visual field defects.

Steroid-induced glaucoma may mimic low tension glaucoma when the steroid-induced pressure elevation has damaged the optic nerve head and visual field in the past, but the IOP has subsequently returned to normal with cessation of the steroid. ${ }^{47}$ Steroid-induced glaucoma may be masked following refractive surgery due to central corneal thinning, ocular rigidity changes, corneal edema or fluid accumulation beneath the LASIK flap. ${ }^{48-50}$

Additional ocular findings from use of topical steroids include mydriasis, increased corneal thickness, corneal ulcers, posterior subcapsular cataracts, delayed wound healing, ptosis and skin atrophy of eyelids. ${ }^{30}$

Eyes with VKC with and without glaucoma have similar corneal topography. Increased IOP associated with steroidinduced glaucoma and VKC may contribute to an increase in the corneal curvature and posterior corneal elevation. These changes may be reversed by a reduction in the IOP with medical therapy. $^{51}$

\section{DIFFERENTIAL DIAGNOSIS}

POAG, uveitic glaucoma, glaucomatocyclitic crisis, normal pressure glaucoma, traumatic glaucoma (esp. unilateral cases) and juvenile glaucoma need to be excluded. Steroid treatment of acute uveitis can suppress inflammation and lead to recovery of aqueous production with resultant increase in IOP, which should not be mistaken as steroid-induced glaucoma. ${ }^{30}$

\section{MANAGEMENT}

Steroid-induced IOP elevation typically occurs within a few weeks of beginning steroid therapy. In the majority of cases, the IOP lowers spontaneously to the baseline within a few weeks to months upon stopping the steroid. ${ }^{52}$ In rare instances, the IOP remains elevated. ${ }^{53}$

The most effective management is discontinuation of the drug and administering antiglaucoma medications till the IOP is reduced. If the patient's underlying medical condition can tolerate discontinuation of corticosteroids, then cessation of the medication usually will result in normalization of IOP. In the case of topical corticosteroid drops, a lower potency steroid medication, such as the phosphate forms of prednisolone and dexamethasone, rimexolone, loteprednol etabonate, fluorometholone, or medrysone, may be substituted. ${ }^{31,32}$ These lower potency drugs have a lesser propensity to raise the IOP, but they usually are not as effective as anti-inflammatory drugs. 
Topical nonsteroidal anti-inflammatory medications (eg, diclofenac, ketorolac) are other alternatives that have no potential to elevate IOP, but they may not have enough antiinflammatory activity to treat the patient's underlying condition. ${ }^{54}$ If subtenon depot steroids are causing an elevation of IOP, they should be excised and removed. ${ }^{22,23}$ It is important to remember that steroids may also cause a rise in the IOP after a filtering surgery and in such patients low potency steroids should be substituted and rapidly tapered. ${ }^{55}$

When medical therapy is ineffective laser or surgery can be tried. In patients with an open angle and the absence of ocular inflammation, laser trabeculoplasty can be attempted to lower the IOP. ${ }^{56,57}$ Selective Laser Trabeculoplasty is a temporizing procedure to consider in patients with steroid-induced elevated IOP. Repeat SLT treatments may be necessary for IOP control. ${ }^{58}$ In patients, whom both medical and laser therapy have failed to lower the IOP adequately, surgical therapy is warranted. ${ }^{53}$ Usually, trabeculectomy with or without intraoperative antimetabolites, is the primary procedure. In cases of eyes with active neovascularization or inflammation, a glaucoma drainage implant may be used as the primary procedure. ${ }^{56,57}$

In eyes with steroid-induced glaucoma and vernal keratoconjunctivitis, prostaglandins should be avoided as they can lead to an exacerbation of symptoms with an increase in the conjunctival inflammation.

Anecortave acetate is a synthetic derivative of cortisol, but very specific and irreversible chemical modifications to the cortisol structure have resulted in the creation of a potent inhibitor of blood vessel growth with no evidence non-clinically or clinically of glucocorticoid receptor-mediated bioactivity. Thus, Anecortave acetate (AA) can be used for the treatment of exudative age-related maculopathy and does not lead to increased IOP. ${ }^{59}$

In fact, an anterior juxtascleral depot of AA has been shown to lower IOP substantially in some eyes with medically uncontrolled steroid-related ocular hypertension. ${ }^{60}$

A prospective long-term evaluation of steroid-induced glaucoma patients reported that patients with steroid-induced glaucoma, who were less than 20 years old, with a higher IOP, and greater glaucomatous optic neuropathy, were more likely to need surgery. After cessation of steroid therapy, all eyes were off treatment at 18 months. $^{61}$

\section{Steroid-induced Glaucoma and Refractive Surgery}

Steroid-induced glaucoma is known to be masked following refractive surgery as IOP recordings are erroneous due to central corneal thinning, ocular rigidity changes, corneal edema or fluid accumulation beneath the LASIK flap. ${ }^{48-50,62}$ Early onset steroidinduced elevation of IOP after LASIK may cause corneal edema and a sudden decrease in visual acuity. Rapid diagnosis and treatment can control IOP and recover the visual loss. ${ }^{63}$

Steroid-induced glaucoma has been reported after photorefractive keratectomy and is known to be underdiagnosed for the same reasons as above. ${ }^{64}$

\section{CONCLUSION}

Careful monitoring of all patients on corticosteroids (especially those with a family history of glaucoma) is warranted. Self medication and injudicious use of steroids should be avoided. If necessary, steroid therapy must be used with intermittent drug holidays and never on a continuous basis.

\section{REFERENCES}

1. Dada T, Konkal V, Tandon R, Sihota R. Corneal topographic response to IOP reduction in steroid induced glaucoma with VKC. Eye 2005;5:122-29.

2. Shepard AR, Jacobson N, Fingert JH, et al. Delayed secondary glucocorticoid responsiveness of MYOC in human trabecular meshwork cells 2001;42:1769.

3. Biedner BA, David R, Grundsky A, Sachs U. Intraocular pressure response to corticosteroids in children. Br J Ophthalmol 1980; 64:430.

4. Becker B. Intraocular pressure response to topical corticosteroids. Invest Ophthalmol Vis Sci 1965;4:198.

5. Armaly MF. Statistical attributes of the steroid hypertensive response in the clinically normal eye.1: The demonstration of three levels of response. Invest Ophthalmol Vis Sci 1965;14:187.

6. Armaly MF. The heritable nature of dexamethasone induced ocular hypertension. Arch Ophthalmol 1966;75:32.

7. Armaly MF. Inheritance of dexamethasone hypertension and glaucoma. Arch Ophthalmol 1967;77:747.

8. Armaly MF. Effect of corticosteroids on IOP and fluid dynamics. III. Changes in visual function and pupil size during topical dexamethasone application. Arch Ophthalmol 1964;71: 636.

9. Armaly MF. Effect of corticosteroids on IOP and fluid dynamics. II. The effects of dexamethasone in the glaucomatous eye. Arch Ophthalmol 1963;70:492.

10. Armaly MF. Effect of corticosteroids on IOP and fluid dynamics. I. The effects of dexamethasone in the normal eye. Arch Ophthalmol 1963;70:88.

11. Pohjola S, Horsmanheimo A. Topically applied corticosteroids in glaucoma capsulare. Arch Ophthalmol 1971;85:150.

12. Becker B, Hahn KA. Topical corticosteroids and heridity in primary open angle glaucoma. Am J Ophthalmol 1964;57: 543.

13. Becker $B$, Chevrette L. Topical corticosteroid testing in glaucoma siblings. Arch Ophthalmol 1966;76:484.

14. Podos SM, Becker B, Morton WR: High myopia and primary open angle glaucoma. Am J Ophthalmol 1966;62:1039.

15. Becker B. Diabetes mellitus and primary open angle glaucoma: the XXVII Edward Jackson Memorial Lecture.Am J Ophthalmol 1971;71:1.

16. Gaston $\mathrm{H}$, et al. Steroid responsiveness in connective tissue diseases. Br J Ophthalmol 1983;67:487. 
17. Spaeth GL . Traumatic hyphema, angle recession, dexamethasone hypertension and glaucoma. Arch Ophthalmol 1967;78:714.

18. Becker B, Podos SM. Krukenberg's spindles and primary open angle glaucoma. Arch Ophthalmol 1966;70:635.

19. Haas JS, Nootens RH. Glaucoma secondary to benign adrenal adenoma. Am J Ophthalmol 1974;78:497.

20. Cubey RB. Glaucoma following the application of corticosteroid to the skin of the eyelids. Br J Dermatol 1976;95:207.

21. Zuerman C, Saunders D, Levit F. Glaucoma from topically applied steroids. Arch Dermatol 1976;112:1326.

22. Herschler J. Intractable intraocular hypertension induced by repository triamcinolone acetonide. Am J Ophthalmol 1972;74:501.

23. Herschler J. Increased intraocular pressure induced by repository corticosteroids. Am J Ophthalmol 1976;82:90.

24. Smithen LM, Ober MD, Maranan L, Spaide RF. Intravitreal triamcinolone acetonide and intraocular pressure. Am J Ophthalmol 2004;138(5):740-43.

25. Dada T, Dhawan M, Garg S, Nair S, Mandal S. Safety and efficacy of intraoperative intravitreal injection of triamcinolone acetonide injection after phacoemulsification in cases of uveitic cataract. J Cataract Refract Surg 2007;33:1613-18.

26. Roth DB, Verma V, Realini T, Prenner JL, Feuer WJ, Fechtner RD.Ophthalmology. Long-term incidence and timing of intraocular hypertension after intravitreal triamcinolone acetonide injection 2009;116(3):455-60.

27. Bernstein HN, Schwartz B. Effects of long-term systemic steroids on ocular pressure and tonographic values. Arch Ophthalmol 1962;68:742.

28. Godel V, Feiler-Ofry V, Stein R. Systemic steroids and ocular fluid dynamics.I, II. Systemic versus topical steroids. Acta Ophthalmol (Copenh) 1972;50:664.

29. Sihota R, Dada T, Rai HK. Fluticasone propionate raises IOP in susceptible individuals. Indian J Ophthalmol 2004;52:170-71.

30. Shields MB. Textbook of Glaucoma (3rd ed). Baltimore, William and Wilkins 1992.

31. Bedrossain RH. Treatment of ocular inflamation with medrysone. Arch Ophthalmol 1969;99:184.

32. Mindel JS, Tavitian HO, Smith H Jr, et al . Comparative ocular pressure elevation by Medrysone, Fluorometholone and dexamethasone phosphate. Arch Ophthalmol 1980;98:1577.

33. Kitazawa Y. Increased IOP induced by corticosteroids. Am J Ophthalmol 1976;82:492.

34. Miller D, Peczon JD, Whitworth CG. Corticosteroids and functions in the anterior segment of the eye. Am J Ophthalmol 1965;59:31.

35. Hernandez MR, et al. Glucocorticoid target cells in human outflow pathway: Autopsy and surgical specimens. Invest Ophthalmol Vis Sci 1983;24:1612.

36. Hayasaka S. Lysosomal enzymes in ocular tissues and diseases. Surv Ophthalmol 1983;27:245.

37. Francois J. The importance of the mucopolysaccharides in IOP regulation Invest Ophthalmol Vis Sci 1975;14:173.

38. Francois J. Tissue culture of ocular fibroblasts. Ann Ophthalmol 1975;11:1551.
39. Hajek AS, et al. Dexamethasone phosphate increases the accumulation of collagen in the cell layer of cultured human trabecular endothelial cells. Invest Ophthalmol Vis Sci 1983;24 (suppl):136.

40. Yun AJ, et al. Proteins secreted by human trabecular cells: glucocorticoids and other effects. Invest Ophthalmol Vis Sci 1989;30:2012.

41. Steely HT, et al. The effects of dexamethasone on fibronectin expresiion in cultured human trabecular meshwork cells Invest Ophthalmol Vis Sci 1992;33:2242.

42. Tripathi BJ, Millard CB, Tripathi RC. Corticosteroids induce a sialated glycoprotein in trabecular cells in vitro. Exp Eye Res 1990;51:735.

43. Bill A. The drainage of aqueous humor. Invest Ophthalmol Vis Sci 1975;14:1.

44. Fingert JH, Clark AF, Craig JE, et al. Evaluation of the myocilin glaucoma gene in monkey and human steroid induced ocular hypertension. Invest Ophthalmol Vis Sci 2001;42:145.

45. Challa, Pratap. Glaucoma Genetics: Advancing New Understandings of Glaucoma Pathogenesis. International Ophthalmology Clinics Spring 2004;44(2):167-85.

46. Mark S. Filla, Xuyang Liu, Thai D. Nguyen, Jon R. Polansky, Curtis R. Brandt, Paul L. Kaufman and Donna M. Peters. In Vitro Localization of TIGR/MYOC in Trabecular Meshwork Extracellular Matrix and Binding to Fibronectin. Investigative Ophthalmology and Visual Science 2002;43:151-61.

47. Alfano JE, Platt D. Steroid induced glaucoma simulating congenital glaucoma. Am J Ophthalmol 1966;61:911.

48. Sugar HS. Low tension glaucoma: A practical approach. Ann Ophthalmol 1979;11:1155.

49. Najman-Vainer J, Smith RJ, Maloney RK. Interface fluid after LASIK: Misleading tonometry can lead to end stage glaucoma. J Cataract Refract Surg 2000;26:471.

50. Knorz MC. Flap and interface complications in LASIK. Curr Opin Ophthalmol 2002;13:242.

51. Dada T, Konkal V, Tandon R, Singh R, Sihota R.Corneal topographic response to IOP reduction in patients of vernal keratoconjunctivitis with steroid induced glaucoma. Eye 2007; 21:158-63.

52. Hamilton DR, Manche EE, Rich LF, et al. Steroid induced glaucoma after LASIK associated with interface fluid. Ophthalmology 2002;109:659.

53. Weinreb RN, Polansky JR, Kramer SG, et al. Acute effects of dexamethasone on IOP in glaucoma. Invest Ophthalmol Vis Sci 1985;26:170.

54. Francois J. Corticosteroid glaucoma. Ann Ophthalmol 1977;9:1075.

55. Strelow SA, Sherwood MB, Broncato LJB, et al. The effect of diclofenac sodium ophthalmic solution on intraocular pressure following cataract extraction. Ophthalmic Surg 1992;23:170.

56. Thomas R, Jay JL. Raised IOP with topical steroids after trabeculectomy. Graefes Arch Clin Exp Ophthalmol 1988;226: 337.

57. Reiss G, Wilensky J, Higginbotham E. Laser trabeculoplasty. Surv Ophthalmol 1991;35:407. 
58. Rubin B, Taglienti A, Rothman RF, Marcus CH, Serle JB. The effect of selective laser trabeculoplasty on intraocular pressure in patients with intravitreal steroid-induced elevated intraocular pressure. J Glaucoma 2008;17:287-92.

59. Anecortave acetate study group. Anecortave acetate as monotherapy for treatment of subfoveal neovascularization in agerelated macular degeneration: Twelve-month clinical outcomes. Ophthalmology 2003;110(12):2372-83.

60. Robin AL, Suan EP, Sjaarda RN, Callanan DG, Defaller J. Reduction of intraocular pressure with anecortave acetate in eyes with ocular steroid injection-related glaucoma Arch Ophthalmol 2009;127:173-78.

61. Sihota R, Konkal VL, Dada T, Agarwal HC, Singh R. Prospective, long-term evaluation of steroid-induced glaucoma. Eye 2008;22:26-30.

62. Lautebach S, Funk J, Reinhard T, Pache M. Steroid glaucoma after laser in situ keratomileusis. Klin Monatsbl Augenheilkd 2007;224:438-40.

63. Frucht-Pery J, Landau D, Raiskup F, Orucov F, Strassman E, Blumenthal EZ, Solomon A. Early transient visual acuity loss after LASIK due to steroid-induced elevation of intraocular pressure. J Refract Surg 2007;23:244-51

64. Yamaguchi T, Murat D, Kimura I, Negishi K, Yuki K, Tsubota K, Ohtake Y. Diagnosis of steroid-induced glaucoma after photorefractive keratectomy. J Refract Surg 2008;24:413-15.

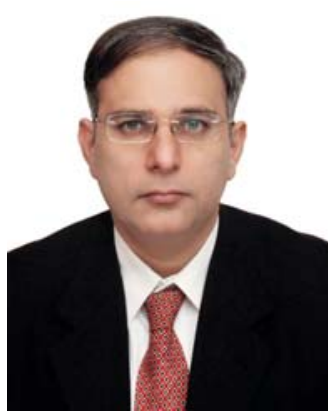

Tanuj Dada (tanujdada@ hotmail.com)

"Every year that I live I am more convinced that the waste of life lies in the love we have not given, the powers we have not used, the selfish prudence which will risk nothing, and which, shrinking pain, misses happiness as well." 